\title{
Salivary lithotripsy in the era of sialendoscopy
}

\author{
La litotrissia salivare nell'era della scialoendoscopia \\ P. CAPACCIO', S. TORRETTA2 ${ }^{2}$, L. PIGNATARO², M. KOCH ${ }^{3}$ \\ ${ }^{1}$ Department of Biomedical, Surgical and Dental Sciences; ${ }^{2}$ Department of Clinical Sciences and Community \\ Health, Fondazione IRCCS Ca' Granda Ospedale Maggiore Policlinico, Università degli Studi di Milano, Milan, Italy; \\ ${ }^{3}$ Department of Otorhinolaryngology, Head and Neck Surgery; Friedrich Alexander University of Erlangen \\ Nuremberg, Germany
}

\section{SUMMARY}

The traditional management of obstructive salivary disorders has been replaced by minimally-invasive gland-preserving techniques including shock-wave lithotripsy, sialendoscopy, interventional radiology and endoscopically video-assisted trans-oral and cervical stone retrieval, of which sialendoscopy is considered to be the method of first choice. Primary endoscopically controlled stone extraction without prior fragmentation is only possible in $15-20 \%$ of cases; in more than $80 \%$, fragmentation is necessary because of the size, impactation and location of the stone, or an alternative treatment such as transoral duct surgery or combined approaches are required. Moreover, about $10-20 \%$ of all stones cannot be adequately accessed by means of a sialendoscope or any alternative surgical method and, in such cases, extra-corporeal shock wave lithotripsy (ESWL) is the treatment of choice. However, in endoscopically accessible stones, ESWL is being gradually replaced by endoscopically assisted intra-corporeal techniques, including endoscopically guided laser and pneumatic intracorporeal lithotripsy. We describe the currently most widely used techniques for salivary lithotripsy, including ESWL, and endoscopically guided laser, electrohydraulic, electrokinetic and pneumatic intra-corporeal lithotripsy, and discuss their indications given the widespread use of advanced rehabilitative sialendoscopy and combined therapeutic approaches.

KEY WORDS: Extracorporeal lithotripsy $\bullet$ Salivary gland $\bullet$ Sialolithiasis $\bullet$ Stones $\bullet$ Obstructive sialadenitis $\bullet$ Laser $\bullet$ Pneumatic lithotripsy

\section{RIASSUNTO}

Negli ultimi decenni i tradizionali approcci terapeutici alla patologia ostruttiva salivare sono stati gradualmente sostituiti da trattamenti conservativi e mini-invasivi tra cui la litotrissia salivare, la scialoendoscopia, le tecniche di radiologia interventistica e la rimozione vidoendoscopica di calcoli per via trans-orale o trans-cervicale. Tra queste tecniche la scialoendoscopia è attualmente considerata il trattamento di scelta, tuttavia la sola scialoendoscopia interventistica non preceduta da tecniche di frammentazione garantisce una completa rimozione dei calcoli salivari all'incirca nel 15-20\% dei casi. Inoltre il 10-20\% dei calcoli non è raggiungibile endoscopicamente o con altri approcci chirurgici. In questi casi la litotrissia salivare extracorporea rappresenta il trattamento di scelta. Nonostante ciò negli ultimi anni la litotrissia salivare extracorporea è stata gradualmente sostituita dalle tecniche di frammentazione intracorporee eseguite sotto controllo endoscopico tra cui la litotrissia salivare intracorporea laser e pneumatica video-assistita. In questo articolo verranno descritte le tecniche e le indicazioni residue alla litotrissia salivare, comprendente la litotrissia extracorporea e la litotrissia salivare intracorporea laser, elettroidraulica, elettrocinetica e pneumatica video-assistite. Verranno inoltre fornite le indicazioni residue di tali trattamenti.

PAROLE CHIAVE: Litotrissia extracorporea $\bullet$ Ghiandola salivare $\bullet$ Scialolitiasi $\bullet$ Calcoli $\bullet$ Scialoadenite ostruttiva $\bullet$ Laser $\bullet$ Litotrissia pneumatica

Acta Otorhinolaryngol Ital 2017;37:113-121

\section{Introduction}

Sialolithiasis is the main cause of obstructive salivary disease: it is detected in about two- thirds of cases, and is responsible for about $50 \%$ of all salivary gland disorders ${ }^{12}$. Some clinical studies have reported that the incidence of symptomatic sialolithiasis is about 60 cases per million per year in the United Kingdom, corresponding to a prevalence of $0.45 \%$, but the prevalence may be higher as post-mortem studies suggest it affects about $1.2 \%$ of the general population ${ }^{34}$.

The traditional management of obstructive salivary disorders (sialadenectomy, duct dilatation and dissection, and sialodochoplasty) has been replaced by minimally-invasive gland-preserving techniques since the observation by van den Akker and Busemann-Sokole ${ }^{5}$ that salivary gland function completely recovers after stone removal. These techniques include shock-wave lithotripsy, sialendoscopy, interventional radiology and endoscopically assisted trans-oral and cervical stone retrieval, which may be used individually or combined, reduce the need for gland removal and its unpleasant complications and loss of function, and assure complete clinical recovery in more than $80 \%$ of patients ${ }^{6}$.

Shock-wave lithotripsy was one of the first to be introduced, and is probably the most standardised of the newer 
techniques. Extra-corporeal shock-wave lithotripsy (ESWL) has been successfully used to treat salivary stones in a way that is similar to that used in urology and gastroenterology since the late 1980s. Shock-wave lithotripsy fragments salivary stones into smaller pieces using te shock-waves generated by the change in impedance at the stone/water interface, which induces a compressive wave that spreads through the stone and an expansive wave that pits and cavitates it, thus making it more easily cleared from the salivary duct system spontaneously after sialogogue-induced salivation, or during endoscopic procedures. The shock waves may be produced extra-corporeally by piezoelectric and electromagnetic techniques, or intra-corporeally by using electro-hydraulic, pneumatic, or laser sources during interventional sialendoscopy ${ }^{7-15}$.

ESWL has many advantages (it is easy to perform, repeatable, safe, generally well-tolerated, and can be carried out on an outpatient basis without anaesthesia), but its main limitation is that the stones often cannot be completely cleared by salivary flow, and small residual fragments remaining inside the ductal system may cause recurrences. It is therefore better if any ESWL treatment is followed by sialendoscopy in order to remove all of the remnants. Other disadvantages are that it is time-consuming (it generally requires repeated 30-minute sessions at intervals of a few weeks) and is not currently approved by the US Food and Drug Administration. For these reasons, together with the cost of the equipment and its maintenance, and the rapid development of advanced interventional sialendoscopic procedures using optical miniaturisation and micro-instruments, fewer centres are now offering ESWL, which is being gradually replaced by endoscopically assisted intra-corporeal techniques for stones which are endoscopically accessible.

\section{Extracorporeal shockwave lithotripsy (ESWL)}

ESWL was first successfully practised for the treatment of sialolithiasis in humans in 1989 by Iro ${ }^{16}$ who used a device designed for renal stones after obtaining encouraging results in animal and in vitro studies. The dedicated instruments that have been designed since then exploit the mechanical damage to stones caused by external shockwaves generated by electromagnetic or piezoelectric sources and uninterruptedly propagated to the stone/tissue interface. At the anterior edge of the stone, some of the shock-waves are reflected and create a compressive force, and some penetrate the stone to its posterior border where they generate further compressive and tensile forces. When these forces exceed the tensile strength of the stone, it fragments but, as the forces are only generated at its anterior and posterior borders (not inside it), repeated applications are required to reach the stone's inner core. The most frequently used source of ESWL is electromagnetic (Fig. 1): an electrical impulse propagated from a

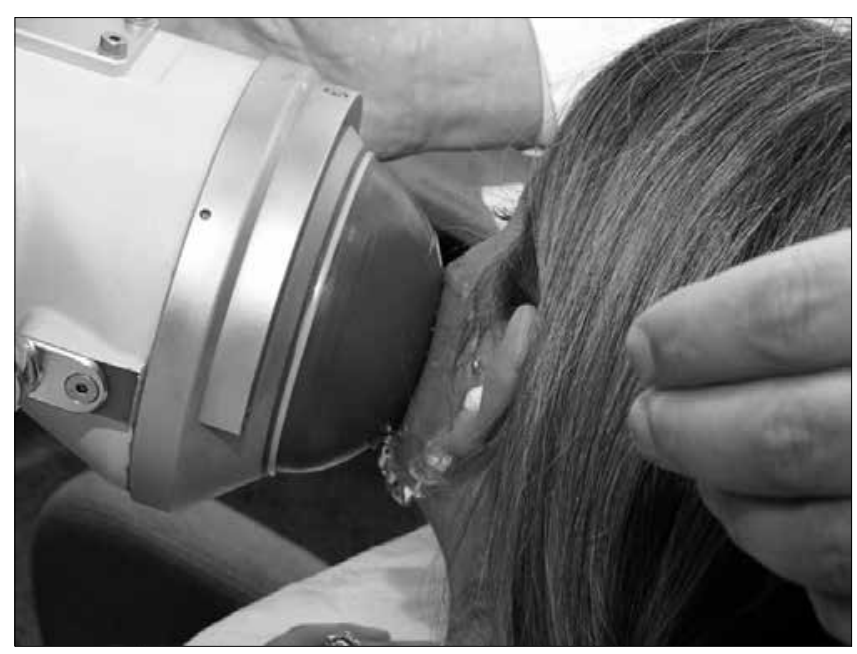

Fig. 1. Extracorporeal lithotripsy of a parotid stone.

generator to a flat coil induces a galvanic change in a nearby metal membrane, and the shock wave propagates into a water coupling medium. When a piezoelectric source is used, a pulse generator produces a high-frequency, highvoltage impulse that simultaneously stimulates all of the ceramic elements making up the piezoelectric acoustic radiator; this leads to their sudden expansion, with the generation of shock waves and their transmission through the water coupling medium.

Ultrasounds are used to focus the shock wave on the stone and continuously monitor the degree of stone fragmentation during each therapeutic session to avoid lesions to the surrounding tissues. It has also recently been suggested that a more advanced contrast-enhanced ultrasonographic diagnostic evaluation could be useful to monitor the degree of glandular vascularisation, which may indicate the presence of chronic inflammation related to sialolithisis, and therefore be an independent and quantitative marker of the effect of treatment ${ }^{17}$.

As the minimum size of the electromagnetic focus is 2.4 $\mathrm{mm}$, only stones larger than $2.4 \mathrm{~mm}$ in diameter are amenable to electromagnetic ESWL treatment, which generally uses a pulse frequency of $0.5-2 \mathrm{~Hz}$ during each session. However, although all stones with a diameter of $>$ $2.4 \mathrm{~mm}$ that can be ultrasonographically detected could theoretically be managed by electromagnetic ESWL ${ }^{18}$, relative contraindications include the presence of a complete distal duct stenosis and pregnancy, the only absolute contraindication is after implantation of a cardiac pacemaker ${ }^{1819}$. Furthermore, in the case of an endoscopically accessible proximal location or a mobile, non-embedded intraductal stone, preferable procedures are interventional sialendoscopy or endoscopically video-assisted transoral or transcutaneous stone retrieval ${ }^{20-24}$. In the event of acute sialadenitis or any other acute inflammatory process of the head and neck region, treatment should be postponed ${ }^{1820}$. Although it is sometimes difficult to make direct com- 
Table I. Results of electromagnetic and piezoelectric extra-corporeal shock wave lithotripsy (ESWL) in the main published studies.

\begin{tabular}{|c|c|c|c|}
\hline & Reference & Site & Success (\%) \\
\hline \multirow{29}{*}{$\begin{array}{l}\text { ELECTRO- } \\
\text { MAGNETIC } \\
\text { ESWL }\end{array}$} & Wehrmann et al., $1994^{8}$ & $\mathrm{P}+\mathrm{SM}$ & $38 / 73(52)$ \\
\hline & \multirow[t]{3}{*}{ Kater et al., $1994^{25}$} & $P$ & $14 / 29(48)$ \\
\hline & & SM & 26/75 (35) \\
\hline & & All & 40/104 (38) \\
\hline & \multirow[t]{3}{*}{ Ottaviani et al., $1996^{9}$} & $P$ & 9/16 (56) \\
\hline & & SM & 15/36 (42) \\
\hline & & All & $24 / 52(46)$ \\
\hline & \multirow[t]{3}{*}{ Ottaviani et al., $1996{ }^{18}$} & $P$ & $14 / 24(58)$ \\
\hline & & SM & 23/56 (41) \\
\hline & & All & $37 / 80(46)$ \\
\hline & \multirow[t]{3}{*}{ Escudier et al., $2003{ }^{10}$} & $P$ & $13 / 32(40)$ \\
\hline & & SM & 27/84 (32) \\
\hline & & All & 40/122 (33) \\
\hline & \multirow[t]{3}{*}{ Capaccio et al., $2004{ }^{26}$} & $P$ & $61 / 88(69)$ \\
\hline & & SM & 84/234 (36) \\
\hline & & All & $145 / 322(45)$ \\
\hline & \multirow[t]{3}{*}{ McGurk et al., $2005^{27}$} & $P$ & 42/88 (48) \\
\hline & & SM & 42/130 (32) \\
\hline & & All & 84/218 (38) \\
\hline & \multirow[t]{3}{*}{ Eggers and Chilla, $2005^{20}$} & $P$ & 15/22 (68) \\
\hline & & SM & 6/16 (37) \\
\hline & & All & 21/38 (55) \\
\hline & \multirow[t]{4}{*}{ Schmitz et al., $2008{ }^{28}$} & $P$ & $18 / 59(39)$ \\
\hline & & SM & 33/126 (26) \\
\hline & & All & $51 / 167(30)$ \\
\hline & & $P$ & $39 / 64(61)$ \\
\hline & \multirow[t]{2}{*}{ Escudier et al., $2010^{29}$} & SM & 28/78 (36) \\
\hline & & All & $67 / 147(47)$ \\
\hline & Guerre and Katz, $2011^{30}$ & $\mathrm{P}+\mathrm{SM}$ & $1056 / 1571(67)$ \\
\hline \multirow{9}{*}{$\begin{array}{l}\text { PIEZO- } \\
\text { ELECTRIC } \\
\text { ESWL }\end{array}$} & \multirow[t]{3}{*}{ Iro et al., $1992^{31}$} & $P$ & $13 / 16(81)$ \\
\hline & & SM & $14 / 35(40)$ \\
\hline & & All & 27/51 (53) \\
\hline & \multirow[t]{3}{*}{ Aidan et al., $1996^{32}$} & $P$ & 1/3 (33) \\
\hline & & SM & 4/12 (33) \\
\hline & & All & 5/15 (33) \\
\hline & Iro et al., $1998{ }^{33}$ & $P$ & $38 / 76(50)$ \\
\hline & Kulkens et al., $2001^{34}$ & $P$ & 26/42 (62) \\
\hline & Zenk et al., $2004{ }^{35}$ & SM & 58/197 (29) \\
\hline
\end{tabular}

P: parotid; SM: submandibular.

parisons of published studies because of the different outcomes considered (e.g. symptomatic recovery, ultrasonographic stone clearance or detection of stone fragments no larger than $2 \mathrm{~mm}$ ), when evaluated as the rate of complete stone clearance, the effectiveness of electromagnetic ES$\mathrm{WL}$ is $26-69 \%$ and that of piezoelectric ESWL is $29-81 \%$ (Table I) ${ }^{8-10} 181925-35$; the success rate is higher in the case of parotid gland stones (electromagnetic ESWL 39-69\% vs 26-42\%; piezoelectric ESWL 33-81\% vs. 29-40\%) (Table I) ${ }^{8-10181925-35}$.

Iro et al. first reported successful fragmentation of a pa- rotid stone ${ }^{16}$ in $1992^{31}$. In 1998, a prospective trial in 76 patients with parotid stones revealed complete success (stone- and complaint-free state) in $50 \%$, partial success in $25 \%$ (complaint-free with residual fragments) and marked improvement of symptoms in $17 \%{ }^{33}$. Compared to this, worse long-term results after treatment of 191 patients with submandibular stones were reported in 2004, showing complete success in $35 \%$, partial success in $15 \%$ (complaint-free with residual fragments) ${ }^{35}$.

In the experience of the University of Milan of about 420 patients treated since 1993 , complete submandibular gland stone clearance (defined as the ultrasonographic absence of any residual stone fragment) has been achieved in $28.4 \%$ of cases with a distal location, and $48.9 \%$ of cases with a hilo-parenchymal location; the corresponding figures for the parotid gland are $70.6 \%$ and $66.7 \%$. Ultrasonographic evidence of residual stone fragments smaller than $2 \mathrm{~mm}$ was observed in $25.9 \%$ of cases of distal and $27.0 \%$ of hilo-parenchymal submandibular gland stones, and in, respectively, $25.9 \%$ and $25.5 \%$ of parenchymal parotid gland stones; residual stone fragments larger than $2 \mathrm{~mm}$ were ultrasonographically detected in $25.2 \%$ and $44.6 \%$ of the submandibular gland stones, and $3.5 \%$ and $7.8 \%$ of the parotid gland stones ${ }^{36}$. Sialadenectomy was performed in $3.1 \%$ of patients (all with submandibular gland stones), and recurrences in the treated gland was observed in only four patients (all of whom achieved complete ultrasonographic stone clearance). Moreover, univariate and multivariate analyses of the findings relating to 322 of the 420 patients after a median follow-up period of 58 months revealed a favourable outcome in patients with parotid gland stones in any location, those with intraductal submandibular gland stones, and stones with a diameter of $<7 \mathrm{~mm}$; in patients aged $<46$ years; and in those receiving fewer than 2000 shock waves ${ }^{26}$. Other studies evaluating the factors influencing ESWL outcomes have confirmed that the site (parotid gland) and size of the stones are the main predictors of clearance ${ }^{29}$ : the smaller the stone, the greater the probability of cure. The site-dependent cure rate may be related to anatomic conditions (i.e. the regular and relatively horizontal course of Stensen's duct), the constitution of the saliva (i.e. the predominantly serous saliva produced by the parotid gland) and practical questions such as the ease with which parotid stones can be identified and targeted ultrasonographically ${ }^{6}$. With regards to stone size, it can be speculated that smaller stones are not generally embedded within the parenchyma or ductal system because they have not had the time to produce tight adherence and can be eliminated more easily.

In the case of partial stone clearance (i.e. the stone is broken sufficiently to allow saliva to pass, but some fragments remain within the ductal system), the power of the shock waves is also important for the outcome of submandibular 
gland stones. Moreover, it is not clear whether their composition affects the success of ESWL (some stones may be more resistant to shock waves than others) or whether incomplete clearance is due to the dynamics of duct salivary flow ${ }^{29}$.

Taken together, our results indicate that patients with parotid gland stones in any location, or peri-hilar or intraparenchymal submandibular gland stones of $<7 \mathrm{~mm}$, may be elective candidates for ESWL.

In terms of safety, only minor, transient and self-resolving side effects have been described, including pain over the treated area (15-100\%), glandular swelling (2-35\%), ductal bleeding (17-71\%) and cutaneous petechiae (6-55\%). There have only been rare reports of acute sialadenitis (2$6 \%$ ), temporary hearing impairment $(2-3 \%)$, temporary

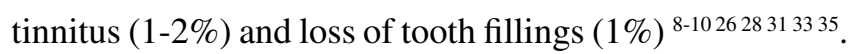

\section{Endoscopically controlled intra-corporeal lithotripsy}

The introduction of interventional sialendoscopy has revolutionised the management of sialolithiasis, leading to generally positive results in submandibular gland stones of $<4$ $\mathrm{mm}$ and parotid gland stones of $<3 \mathrm{~mm}^{1}$. However, stones of $>4 \mathrm{~mm}$ and stones embedded deeply in the smallest intra-glandular ductal divisions may be treated using endoscopically controlled intra-corporeal lithotripsy.

Intra-corporeal lithotripsy exploits the shock waves generated by a lithotripsy probe that is inserted into the salivary duct system under endoscopic guidance, and directly reaches the stone's surface ${ }^{37}$. Shock wave sources include laser beams, pneumatic devices and electro-hydraulic or electrokinetic probes.

However, electro-hydraulic lithotripsy, electrokinetic lithotripsy and pneumatic lithotripsy are all modifications of kinetic or ballistic lithotripsy, and therefore associated with the potential disadvantages of mechanical tissue trauma (e.g. duct perforation) or the propulsion of stones into the proximal/intra-parenchymal duct system or paraductal tissue ${ }^{1238-40}$.

In all forms of intra-corporeal lithotripsy, the effectiveness and duration of treatment depends first on the endoscopic accessibility, second on the size, shape and location of the stone and third on the anatomic relationships within the salivary duct system ${ }^{2041} 42$. Regarding submandibular stones located near the mylohyoid bend, transoral duct surgery or ESWL are valid treatment alternatives and the use of intraductal lithotripsy must be weighed in every individual case or can be applied in combination with these 204143 .

\section{Intra-corporeal electro-hydraulic lithotripsy}

Intra-corporeal electro-hydraulic lithotripsy (EHL) involves a very fast electrical discharge at the tip of a probe that provokes a local extension of plasma which, together with the subsequent collapse of a cavitation bubble, creates abrupt micro-shock waves that indirectly lead to stone fragmentation when combined with a high-speed microwater jet. However, although the fragmentation is sufficient, the method has the significant disadvantage that it traumatically lacerates tissue in in vitro experiments and animal tests, as well as during its clinical application. The high risk of iatrogenic ductal injury and the relative ineffectiveness of the procedure at reduced voltages has led to it being gradually abandoned ${ }^{39}{ }^{44}$, and it is longer considered a method of choice.

The published clinical results relate to only a few patients and, as the majority of articles provide no detailed data concerning procedures, success rates or side effects, it is difficult to judge the effect/risk ratio of the technique ${ }^{1111345-50}$. It was first used in 1993 by Konigsberger, who placed a flexible endoscope and a probe supplying shock waves (Calcutript ${ }^{\mathrm{TM}}$, Storz, Tuttlingen, Germany) $1 \mathrm{~mm}$ in front of the Wharton's duct stones of 29 patients (no information is given about the glands) ${ }^{11}$. Complete fragmentation was achieved in $66 \%$ of cases, but there are no numbers concerning stone/complaintfree rates. The glands were preserved in $79.3 \%$ of cases, but nothing was said about side effects. Nakyama et al. ${ }^{48}$ treated a submandibular gland stone using intraductal EHL (Autolith ${ }^{\mathrm{TM}}$, Northgate Technology, Scottsdale Court Elgin, IL, USA) and reported complete fragmentation and complete success.

\section{Intra-corporeal electrokinetic lithotripsy}

The principle underlying electrokinetic lithotripsy (EKL) is the generation of kinetic impulses by means of highpower electrical and magnetic fields that produce electromagnetic energy. The energy is transmitted to a probe that generates shock waves and impulses that are directed towards the surface of a stone.

Modayil et al. ${ }^{38}$ used EKL (EKL Compact ${ }^{\mathrm{TM}}$, Olympus, Tokyo, Japan) in one case, and obtained complete fragmentation; the patient was reported to be complaint-free. However, a significant disadvantage of EKL is that it is noisy, which has negative effects on the auditory system when applied to the head and neck region. Consequently, although EKL is effective in the case of nephrolithiasis ${ }^{40}$, techniques such as laser or pneumatic lithotripsy are currently preferred in the case of sialolithiasis.

\section{Intra-corporeal pneumatic lithotripsy}

Pneumatic lithotripsy (PL) is mainly based on releasing pneumatic energy from $\mathrm{CO}_{2}$ gas, and transmitting it to a probe that directs kinetic energy to the surface of a stone. Direct contact with the stone is required to cause fragmentation. The gas can be released from a central connecting system or a cartridge (which allows greater mobility, better handling and independence from infrastructure).

The use of the technique to treat sialolithiasis was first 
tested in the 1990s, but not under direct endoscopic control because no suitable mini-sialendoscopes, probes, or micro-instruments were available. The results of in vitro and in vivo trials showed that PL can be effective in treating salivary gland stones, but the observation of tissue damage due to the propulsion of fragments into the duct wall and a tendency to penetrate the surrounding tissue meant that the technique was not widely accepted at the time ${ }^{12}$.

In order to allow direct endoscopic control, it was necessary to use rigid endoscopes with a diameter of $>2 \mathrm{~mm}$ (which made it difficult to insert and/or manoeuvre them within the duct system); if smaller endoscopes were used, the probe could not fit in any of the working channels but had to be inserted parallel to the endoscope, which hindered effective interventional therapy. Only two later publications describe the use of PL in a few patients. Arzoz et al. ${ }^{13}$ treated nine of 18 patients (Lithoclast ${ }^{\mathrm{TM}}$, EMS Swiss, Nyon, Switzerland), but did not specify the glands and, although the overall success and gland preservation rates were, respectively, $80 \%$ and $89 \%$, they did not provide any specific data concerning the effectiveness of PL. Serbetci et al. ${ }^{49}$ described treatment of two patients (no glands were specified) with Calcusplit ${ }^{\mathrm{TM}}$ (Storz, Tuttlingen, Germany); complete fragmentation and a stone-free state was achieved in one (success rate $50 \%$ ).

A new, small and lightweight hand-held PL device (StoneBreaker ${ }^{\mathrm{TM}}$, Cook Medical, Bloomington, USA) became available at the end of October 2014. It has an integrated gas cartridge that makes it independent of immobile gas sources, and the pneumatic energy released by a trigger mechanism can be transmitted to the surface of a stone under direct endoscopic control by means of an exchangeable nitinol probe with a diameter of $0.56 \mathrm{~mm}$ (small enough to fit into the working channel) although, like all of the other methods of intraductal fragmentation, it depends on the accessibility of the stone (Fig. 2).

Koch et al. published the first description of the use of this device in the only paper that reports the results of the PL treatment of salivary stones ${ }^{51}$. They treated 49 stones (19 submandibular gland and 23 parotid gland stones) in 44

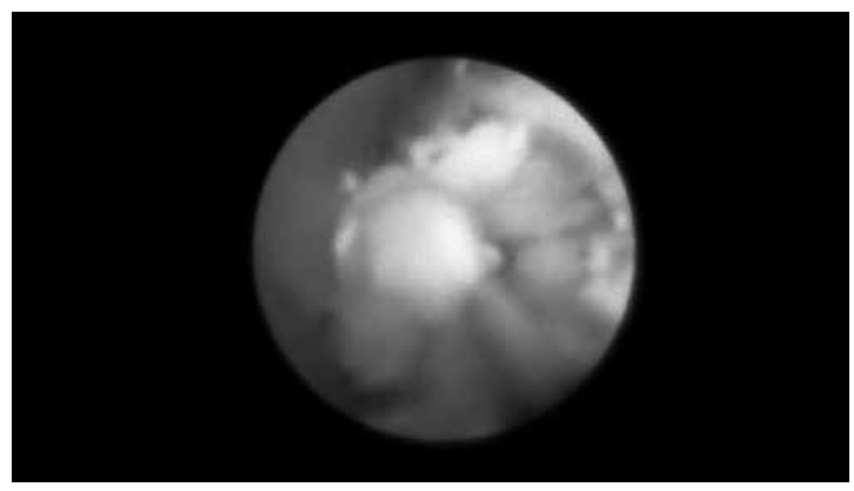

Fig. 2. Intracorporeal pneumatic lithotripsy of a parotid stone. patients: 40 patients had one stone, three had two stones and one had three stones. Complete fragmentation was achieved in $98 \%$ of cases $(96 \%$ of the submandibular gland stones and $100 \%$ of the parotid gland stones), and $98 \%$ of patients became stone free $(100 \%$ of those with submandibular gland stones and $95 \%$ of those with parotid gland stones). All of the patients retained their glands and became complaint free. Complete success was achieved in $98 \%$ of cases $(100 \%$ of the submandibular gland stones and $95 \%$ of the parotid gland stones), although five patients (11.4\%) required additional treatment to achieve successful therapy: transoral duct surgery of submandibular gland stones in two cases, and ESWL in three (one submandibular and two parotid gland stones). PL seems to be indicated in the case of impacted/immobile post-hilar submandibular gland stones that are not indicated for extended transoral duct surgery. PL may be indicated in all parotid gland stones that can be accessed with a sialendoscope 2051 .

Like all of the other forms of intra-corporeal lithotripsy, the effectiveness and duration of treatment depend on the size, shape and location of the stone, and the anatomic relationships of the salivary duct system 204142 .

\section{Intra-corporeal laser lithotripsy}

Endoscopically controlled intra-corporeal laser lithotripsy is based on the principle that the absorption of laser pulses causes the formation of a rapidly expanding cavity of ions and electrons on the stone surface leading to high-pressure shock waves that fragment the stone. As energy absorption is material-dependent and human stones generally absorb wavelengths of 300-800 nm, moderate energy corresponding to about $20-100 \mathrm{~mJ}$ is generally needed to break down the stone. However, only $60 \%$ of the shock waves actually penetrate the stone, whereas about $40 \%$ are reflected from its surface and may cause thermal events ${ }^{52}$ leading to ductal wall perforation, tissue damage and coagulation.

Endoscopically controlled laser lithotripsy has become a routine procedure for the fragmentation of urinary stones, and has also been used to treat sialolithiasis with positive preliminary results ${ }^{4353-55}$ (Fig. 3). It was first used to treat

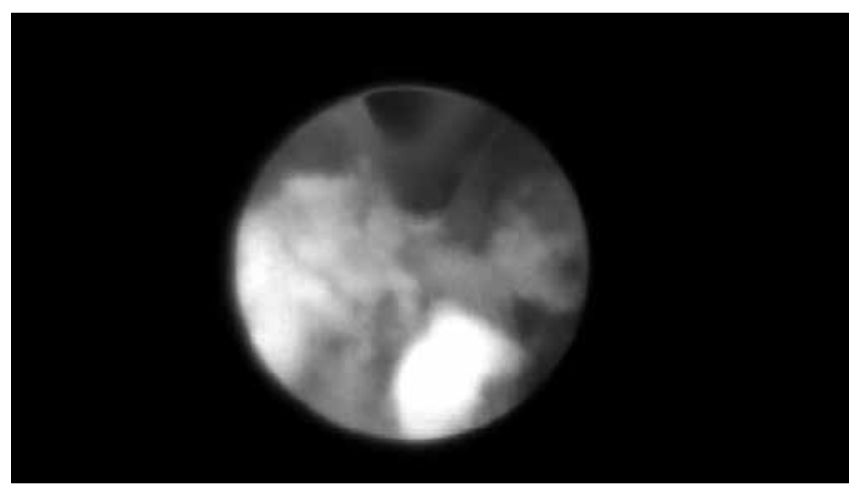

Fig. 3. Intracorporeal laser lithotripsy of a submandibular stone. 
salivary stones in 1990, when Gundlach reported $92 \%$ of stone clearance using a pulsed excimer laser ${ }^{55}$. Subsequently, Marchal and Raif \& Nahlieli et al. ${ }^{5657}$ showed that holmium and erbium laser lithotripsy improved the overall rate of successful removal of complicated stones from $35 \%$ to $70 \%$ and, since then, various laser systems have been designed that use gas (e.g. excimer), liquid (e.g. dye) or solid substances (e.g. alexandrite, neodymium:yttriumaluminum-garnet [YAG], holmium:YAG, erbium:YAG, thulim:YAG) as amplification media. However, there is a relative paucity of publications on these techniques.

The results of holmium:YAG and pulsed dye intra-corporeal laser lithotripsy have been reported in limited case series ${ }^{1458}$ : the former is associated with a high risk of soft tissue damage due to energy absorption by surrounding tissue and a thermal effect; the latter is more manageable, but very expensive ${ }^{52}$.

In the literature, the reported success rates after laser lithotripsy range from 40 to $90 \%{ }^{58}$.

As shown in Table II, according to the results from recent studies the rate of successful stone extraction ranges from $81 \%$ to $100 \%{ }^{164353-555759}$; failures are mainly due to invisible stones in stenotic or tortuous ducts ${ }^{59}$. Some recent publications reported success rates of more than $80 \%$, most often after application of Holmium-YAG-lasera and this type of laser was positively rated in terms of its properties of fragmentation. 4353546061 . It is not yet known whether salivary stone composition may affect outcomes, but some experimental studies using in vitro models have shown that a Ho:YAG laser seems to be effective in disintegrating stones regardless of the physical and radiological characteristics ${ }^{62}$. Together with the results after clinical use of this type of laser published in recent studies and taking into account the cost-effectiveness of the method, a holmium:YAG laser seems to be the favorable alternative if laser lithotripsy is intended.

On the basis of this experience, it has been suggested that endoscopically controlled intra-corporeal laser lithotripsy could be used to remove moderately sized stones $(<7-10 \mathrm{~mm})$ located within the gland itself or in the parotid duct.
The main risks of endoscopically controlled laser lithotripsy are thermal injuries to the surrounding soft tissue, vessels and nerves, and ductal wall perforation, which may occur in up to $13 \%$ of cases ${ }^{59}$. The former can be avoided by means of careful irrigation, which is also useful for stone removal; however, it is necessary to remember that strong irrigation may predispose to the development of oedema of the oral floor of the mouth and the gland tissue.

Because of the long duration of the procedure and the need for repeated passages, papilla stenosis is also possible, warranting papillotomy in a substantial proportion of the submandibular cases.

Endoscopically controlled intra-corporeal laser lithotripsy is a time-consuming procedure, particularly in the case of multiple stones, because there is a learning curve for sialendoscopy and laser lithotripsy, and the time required directly correlates with the size of the stone ${ }^{48}$.

\section{Conclusions}

Interventional sialendoscopy is currently considered the method of first choice. Mobile stones with a size of 3-5 $\mathrm{mm}$ can be retrieved (primarily by means of a basket or forceps) with success rates of more than $80 \%$ if the indication is appropriate ${ }^{565863}$. The literature suggests that primary endoscopically controlled stone extraction without prior fragmentation is only possible in $15-20 \%$ of stones, and more than $80 \%$ require fragmentation because of their size, impactation and location, or need to be treated by transoral duct surgery or combined approaches 62024335864 .

Various methods of endoscopically-assisted intraductal fragmentation of salivary stones have been proposed in the literature with success rates of more than $80 \%{ }^{111} 131538$ 44-5153-61 65. Currently, laser and pneumatic lithotripsy are most often used and many experiences have been reported after application of a holmium:YAG laser $13154345-47495153-6165$. For the 10-20\% of stones that cannot be accessed using a sialendoscope or any other surgical method, ESWL is the treatment of choice and

Table II. Results of endoscopically controlled intra-corporeal laser lithotripsy in the main published studies.

\begin{tabular}{llcc} 
Reference & Laser type & Site & Success (\%) \\
Gundlach et al., $1990^{55}$ & Pulsed excimer & SM & $11 / 12(92)$ \\
Ito et al., $1996{ }^{15}$ & Pulsed dye & SM & $15 / 15(100)$ \\
Raif et al., $2006^{57}$ & Erbium:YAG & SM+P & $15 / 18(83)$ \\
Durbec et al., $2012^{59}$ & Thulium:YAG & P & $37 / 40(92)$ \\
& & SM & $22 / 23(96)$ \\
Martellucci et al., $2013^{53}$ & Holmium:YAG & All & $59 / 63(94)$ \\
Phillips and Withrow, $2014{ }^{43}$ & Holmium:YAG & SM & $13 / 16(81)$ \\
Sionis et al., $2014{ }^{54}$ & Holmium:YAG & SM+P & $13 / 16(81)$ \\
\hline
\end{tabular}

P: parotid; SM: submandibular. 
Table III. Results of pneumatic lithotripsy at the University of Erlangen ${ }^{51}$.

\begin{tabular}{|c|c|c|c|c|}
\hline Parameter Mean \pm SEM & $\begin{array}{c}\text { Total glands } \\
\text { (Patients } n=44 \text {, } \\
\text { Stones } n=49 \text { ) }\end{array}$ & $\begin{array}{l}\text { Submandibular } \\
\text { gland } \\
\text { (Patients } n=25 \text {, } \\
\text { Stones } n=26 \text { ) }\end{array}$ & $\begin{array}{c}\text { Parotid } \\
\text { gland } \\
\text { (Patients } n=19 \\
\text { Stones } n=23 \text { ) }\end{array}$ & $\begin{array}{c}\text { Mann- } \\
\text { Whitney-U- } \\
\text { test }\end{array}$ \\
\hline Size of stone $(\mathrm{mm})$ & $6.75 \pm 0.37$ & $6.38 \pm 0.32$ & $7.17 \pm 0.71$ & n.s. \\
\hline $\begin{array}{l}\text { Number of } \\
\text { lithotripsies/stone (n) }\end{array}$ & $1.09 \pm 0.07$ & $1.09 \pm 0.10$ & $1.08 \pm 0.11$ & n.s. \\
\hline $\begin{array}{l}\text { Number of } \\
\text { shock waves/stone (n) }\end{array}$ & $83.43 \pm 14.93$ & $102.27 \pm 22.62$ & $62.13 \pm 18.54$ & $p=0.05$ \\
\hline Duration of lithotripsy/stone (min.) & $50.51 \pm 6.04$ & $64.57 \pm 9.11$ & $34.61 \pm 6.43$ & $p=0.0001$ \\
\hline $\begin{array}{l}\text { Number of stones with } \\
\text { complete fragmentation (n, \%) }\end{array}$ & $48 / 49(97.9 \%)$ & $25 / 26(96 \%)$ & 23/23 (100\%) & n.s. \\
\hline $\begin{array}{l}\text { Number of patients } \\
\text { stone-free (n, \%) }\end{array}$ & $43 / 44(97.7 \%)$ & $25 / 25(100 \%)$ & $18 / 19(94.7 \%)$ & n.s. \\
\hline $\begin{array}{l}\text { Number of patients } \\
\text { complaint-free (n, \%) }\end{array}$ & $44 / 44(100 \%)$ & $25 / 25(100 \%)$ & $19 / 19(100 \%)$ & n.s. \\
\hline
\end{tabular}

can be successful in up to $80 \%$ of cases, particularly under ultrasound guidance 62325 30-36415765. It should finally be mentioned that a combination of extra-corporeal and intra-ductal fragmentation may further increase success rates 20236465 . If treatment is performed according to proven treatment algorithms, which is the case in most acknowledged salivary gland centres, the gland resection rate is clearly below $3-5 \%$.

\section{References}

1 Marchal F, Dulguerov P, Becker M, et al. Specificity for parotid sialendoscopy. Laryngoscope 2001;111:264-71.

2 Epker BN. Obstructive and inflammatory diseases of the major salivary glands. Oral Surg Oral Med Oral Pathol 1972;33:2-27.

3 Rauch S, Gorlin RJ. Diseases of the salivary glands. In: Gorlin RJ, Goldman HM, editors. Thoma's Oral Pathology. $6^{\text {th }}$ edition, vol 2. St Louis: Mosby; 1970. p. 997-1003.

4 Brown AL, Shepherd D, Buckenham TM. Per oral balloon sialoplasty: results in the treatment of salivary duct stenosis. Cardiovasc Intervent Radiol 1997;20:337-42.

5 Van den Akker HP, Busemann-Sokole E. Submandibular gland function following transoral sialolithectomy. Oral Surg Oral Med Oral Pathol 1983;56:351-6.

6 Iro H, Zenk J, Escudier MP, et al. Outcome of minimally invasive management of salivary calculi in 4,691 patients. Laryngoscope 2009;119:263-8.

7 Iro H, Schneider T, Nitsche N, et al. Extracorporeal piezoelectric lithotripsy of salivary calculi: initial clinical experiences. HNO 1990;38:251-5.

8 Wehrmann T, Kater W, Marlinghaus EH, et al. Shock wave treatment of salivary duct stones: substantial progress with a minilithotripter. Clin Invest 1994;72:604-8.

9 Ottaviani F, Capaccio P, Campi M, et al. Extracorporeal electromagnetic shock-wave lithotripsy for salivary gland stones. Laryngoscope 1996;106:761-4.

${ }^{10}$ Escudier MP, Brown JE, Drage NA, et al. Extracorporeal shockwave lithotripsy in the management of salivary calculi. Br J Surg 2003;90:482-5.

11 Konigsberger R, Freyh J, Goetz A, et al. Endoscopicallycontrolled electrohydraulic intracorporeal shock wave lithotripsy (EISL) of salivary stones. J Otolaryngol 1993;22:12-3.

12 Iro H, Benzel W, Gode U, et al. Pneumatic intracorporeal lithotripsy of salivary stones: an in vitro and in vivo animal investigation. HNO 1995;43:172-6.

13 Arzoz E, Santiago A, Esnal F, et al. Endoscopic intracorporeal lithotripsy for sialolithiasis. J Oral Maxillofac Surg 1996;54:847-50.

14 McGurk M, Prince MJ, Jang ZX, et al. Laser lithotripsy: a preliminary study on its application for sialolithiasis. $\mathrm{Br} \mathbf{J}$ Oral Maxillofac Surg 1994;32:218-21.

15 Ito H, Baba S. Pulsed dye laser lithotripsy of submandibular gland salivary calculus. J Laryngol Otol 1996;110:218-21.

16 Iro H, Nitsche N, Schneider TH, et al. Extracorporeal shockwave lithotripsy of salivary gland stones. Lancet 1989;2:115.

17 Siedek V, Clevert DA, Rytvina M, et al. Contrast-enhanced ultrasound for monitoring effects of extracorporeal shock wave sialolithotripsy in sialolithiasis. Laryngoscope 2012;122:1301-5.

18 Ottaviani F, Capaccio P, Rivolta R, et al. Salivary gland stones: US evaluation in shock wave lithotripsy. Radiology 1997;204:437-41.

19 Eggers G, Chilla R. Ultrasound guided lithotripsy of salivary calculi using an electromagnetic lithotriptor. J Oral Maxillofac Surg 2005;34:890-4.

20 Koch M, Zenk J, Iro H. Algorithms for treatment of salivary gland obstructions. Otolaryngol Clin North Am 2009;42:1173-92.

21 Makdissi J, Escudier MP, Brown JE, et al. Glandular function after intraoral removal of salivary calculi from the hilum of the submandibular gland. Br J Oral Maxillofac Surg 2004;42:538-41.

${ }^{22}$ McGurk M, Makdissi J, Brown JE. Intra-oral removal of stones from the hilum of the submandibular gland: report of technique and morbidity. Int J Oral Maxillofac Surg 2004:33:683-6. 
${ }^{23}$ Zenk J, Koch M, Klintworth N, et al. Sialendoscopy in the diagnosis and treatment of sialolithiasis: a study on more than 1000 patients. Otolaryngol Head Neck Surg 2012;147:858-63.

24 Witt RL, Iro H, Koch M, McGurk M, et al. Minimally invasive options for salivary calculi. Laryngoscope 2012;122:1306-11.

25 Kater W, Meyer WW, Wehrmann T, et al. Efficacy, risks, and limits of extracorporeal shock wave lithotripsy for salivary gland stones. J Endourol 1994;8:21-4.

26 Capaccio P, Ottaviani F, Manzo R, et al. Extracorporeal lithotripsy for salivary calculi: a long-term clinical experience. Laryngoscope 2004;114:1069-1073.

27 McGurk M, Escudier MP, Brown JE. Modern management of salivary calculi. Br J Surg 2005;92:107-12.

28 Schmitz S, Zengel P, Alvir I. Long-term evaluation of extracorporeal shoch-wave lithotripsy in the treatment of salivary stones. J Laryngol Otol 2008;122:165-71.

29 Escudier MP, Brown JE, Putcha V, et al. Factors influencing the outcome of extracorporeal shock wave lithotripsy in the management of salivary calculi. Laryngoscope 2010;120:1545-9.

${ }^{30}$ Guerre A, Katz P. Extracorporeal shockwave lithotripsy (ESWL) for salivary gland stones: a retrospeticve study of 1571 patients. Rev Stomatol Chir Maxillofac 2011;112:75-9.

31 Iro H, Schneider HT, Fodra C, et al. Shockwave lithotripsy of salivary duct stones. Lancet 1992; 339:1333-6.

32 Aidan P, De Kerviler E, LeDuc A, et al. Treatment of salivary stones by extracorporeal lithotripsy. Am J Otolaryngol 1996; 17:246-50.

33 Iro H, Zenk J, Waldfahrer F, et al. Extracorporeal shock wave lithotripsy of parotid stones. Results of a prospective clinical trial. Ann Otol Rhinol Laryngol 1998;107:860-4.

34 Kulkens C, Quetz JU, Lippert BM. Ultrasound-guided piezoelectric extracorporeal shock wave lithotripsy of parotid gland calculi. J Clin Ultrasound 2001;29:389-94.

35 Zenk J, Bozzato A, Winter M, et al. Extracorporeal shockwave lithotripsy of submandibular stones: evaluation after 10 years. Ann Otol Rhinol Laryngol 2004;113:378-83.

${ }^{36}$ Capaccio P, Torretta S, Pignataro L. Extracorporeal lithotripsy techniques for salivary stones. Otolaryngologic Clin North Am 2009;42:1139-59.

37 Nahlieli O, Baruchin A. Endoscopic technique for the diagnosis and treatment of obstructive salivary gland diseases. $\mathrm{J}$ Oral Maxillofac Surg 1999;57:1394-401.

38 Modayil PC, Jacob V, Manjaly G, et al. Intracorporeal electrokinetic lithotripsy: an advancement in minimally invasive management of parotid duct calculus. J Laryngol Otol 2008;122:428-31.

39 Iro H, Zenk J, Hosemann WG, et al. Electrohydraulic intracorporeal lithotripsy of salivary calculi. In vitro and animal experiment studies. HNO 1993;41:389-95.

40 Keeley FX, Jr., Pillai M, Smith G, et al. Electrokinetic lithotripsy: safety, efficacy and limitations of a new form of ballistic lithotripsy. BJU International 1999;84:261-3.

${ }^{41}$ Capaccio P, Torretta S, Ottaviani F, et al. Modern management of obstructive salivary diseases. Acta Otolaryngol Ital 2007;27:161-72.
42 Luers JC, Grosheva M, Stenner M, et al. Sialoendoscopy: prognostic factors for endoscopic removal of salivary stones. Arch Otolaryngol Head Neck Surg 2011;137: 325-9.

43 Phillips J, Withrow K. Outcomes of holmium laser-assisted lithotripsy with sialendoscopy in treatment of sialolithiasis. Otolaryngol Head Neck Surg 2014;150:962-7.

${ }^{44}$ Bayar N, Kaymaz FF, Apan A, et al. Effects of electrohydraulic extracorporeal shock wave lithotripsy on submandibular gland in the rat: electron microscopic evaluation. Int $\mathrm{J}$ Ped Otolaryngol 2002;63:223-33.

45 Marchal F, Dulguerov P, Becker M, et al. Submandibular diagnostic and interventional sialendoscopy: new procedure for ductal disorders. Ann Otol Rhinol Laryngol 2002;111:27-35.

46 Papadaki ME, McCain JP, Kim K, et al. Interventional sialoendoscopy: early clinical results. J Oral Maxilofac Surg 2008;66:954-62.

47 Pace CG, Hwang KG, Papadaki M, et al. Interventional sialoendoscopy for treatment of obstructive sialadenitis. J Otol Maxillofac Surg 2014;72:2157-66.

48 Nakayama E, Okamura K, Mitsuyasu T, et al. A newly developed interventional sialendoscope for a completely nonsurgical sialolithectomy using intracorporeal electrohydraulic lithotripsy. J Oral Maxillofac Surg 2007;65:1402-5.

49 Serbetci E, Sengor GA. Sialendoscopy: experience with the first 60 glands in Turkey and a literature review. Ann Otol Rhinol Laryngol; 119:155-64.

50 Nahlieli O, Shacham R, Bar T, et al. Endoscopic mechanical retrieval of sialoliths. Oral Surg Oral Med Oral Pathol Oral Radiol Endod 2003;95:396-402.

51 Koch M, Mantsopoulos K, Schapher M, et al. Intraductal pneumatic lithotripsy for salivary stones with the StoneBreaker: Preliminary experience. Laryngoscope 2016;126:1545-50.

52 Mulvaney WP, Beck CW. The laser beam in urology. J Urol 1968;99:112-5.

53 Martellucci S, Pagliuca G, de Vincentiis M, et al. Ho:Yag laser for sialolithiasis of Wharton's duct. Otolaryngol Head Neck Surg 2013;148:770-4.

54 Sionis S, Caria RA, Trucas M, et al. Sialoendoscopy with and without holmium:YAG laser-assisted lithotripsy in the management of obstructive sialadenitis of major salivary glands. Br J Oral Maxillofac Surg 2014;52:58-62.

55 Gundlach P, Scherer H, Hopf J, et al. Endoscopic-controlled laser lithotripsy of salivary calculi: in vitro studies and initial clinical use. HNO 1990;38:247-50.

56 Marchal F, Becker M, Dulguerov PO, et al. Interventional sialendoscopy. Laryngoscope 2000;110:318-20.

57 Raif J, Vardi M, Nahlieli O, et al. An Er:YAG laser endoscopic fiber delivery system for lithotripsy of salivary stones. Lasers Surg Med 2006;38:580-7.

58 Marchal F, Dulguerov P. Sialolithiasis management: the state of art. Arch Otolaryngol Head Neck Surg 2003;129:951-6.

59 Durbec M, Dinkel E, Vigier S, et al. Thulium-YAG laser sialendoscopy for parotid and submandibular sialolithiasis. Lasers Surg Med 2012;44:783-6.

60 Sun YT, Lee KS, Hung SH, et al. Sialendoscopy with holmium:YAG laser treatment for multiple large sialolithi- 
ases of the Wharton duct: a case report and literature review. J Oral Maxillofac Surg 2014;72:2491-6.

${ }_{61} \mathrm{Su} \mathrm{CH}$, Lee KS, Tseng TM, et al. Endoscopic holmium:YAG laser-assisted lithotripsy: a preliminary report. B-Ent 2015;11:57-61.

62 Schrötzlmair F, Müller M, Pongratz T, et al. Laser lithotripsy of salivary stones: correlation with physical and radiological parameters. Lasers Surg Med 2015;47:342-9.
63 Koch M, Zenk J, Iro H. Diagnostic and interventional sialoscopy in obstructive diseases of the salivary glands. HNO 2008;56:139-44.

${ }^{64}$ Nahlieli O, Shacham R, Zaguri A. Combined external lithotripsy and endoscopic techniques for advanced sialolithiasis cases. J Oral Maxillofac Surg 2010;68:347-53.

65 Katz P. New techniques for the treatment of salivary lithiasis: sialoendoscopy and extracorporal lithotripsy: 1773 cases. Ann Otolaryngol Chir Cervicofac 2004;121:123-32.

Received: September 15, 2016 - Accepted: December 12, 2016

Address for correspondence: Pasquale Capaccio, Department of Biomedical, Surgical and Dental Sciences, University of Milan, Fondazione IRCCS Ca' Granda Policlinico, via F. Sforza 35, 20122 Milano, Italy. Tel. +39 02 55032563. E-mail: pasquale.capaccio@ unimi.it 